\title{
The left atrial appendage: Won't get fooled again
}

\author{
Marc Gillinov, MD
}

\author{
From the Department of Thoracic and Cardiovascular Surgery, The Cleveland Clinic, Cleveland, Ohio. \\ Disclosures: Author has nothing to disclose with regard to commercial support. \\ Received for publication June 20, 2016; accepted for publication June 21, 2016; available ahead of print Aug 2, \\ 2016. \\ Address for reprints: Marc Gillinov, MD, Department of Thoracic and Cardiovascular Surgery, Cleveland Clinic, \\ Desk J4-1, 9500 Euclid Ave, Cleveland, OH 44195 (E-mail: gillinom@ccf.org). \\ J Thorac Cardiovasc Surg 2016;152:1081-2 \\ $0022-5223 / \$ 36.00$ \\ Copyright (C) 2016 by The American Association for Thoracic Surgery \\ http://dx.doi.org/10.1016/j.jtcvs.2016.06.032
}

We have been fooling ourselves. Every time we complete an operation and dictate the words, "The left atrial appendage (LAA) was excised (or excluded) with suture (or a stapler)," we do so with confidence, certain that in our hands the LAA has been managed successfully. In their randomized, prospective pilot comparison of 3 atrial appendage elimination techniques appearing in this issue of the Journal, however, Lee and colleagues, a group of expert surgeons, demonstrate that our confidence is misplaced. Standard surgical management of the LAA is unsuccessful in the majority of cases.

\section{WHAT DID THIS STUDY FIND?}

In comparing 3 different techniques for LAA management - internal ligation, stapled excision, and surgical excision-the study demonstrated that none was uniformly successful in either the short term or the long term; the overall failure rate was $57 \%$. Early failures consisting of bleeding, persistent blood flow, and residual stumps were common, and at 3 months of follow-up, additional failures were evident on transesophageal echocardiography. Lee and colleagues ${ }^{1}$ suggest an important action item on the basis of these findings. The integrity of LAA management should be assessed by focused intraoperative transesophageal echocardiography. Identification of residual blood flow or a stump exceeding $1 \mathrm{~cm}$ should prompt further treatment during the index operation; this would generally consist of additional sutures placed from the epicardial aspect of the appendage.

\section{WHAT DID THIS STUDY NOT FIND?}

There were no strokes among the 28 patients treated, suggesting the possibility that incomplete LAA management may not be harmful. Lee and colleagues ${ }^{1}$ address this point, noting that percutaneous LAA management often leaves residual flow but still reduces stroke risk. That said, it is safe to presume that all surgeons would choose successful, complete LAA treatment rather than options that are often unsuccessful and incomplete.

The most important outstanding question-does LAA management in surgical patients reduce the long-term risk of stroke-cannot be answered unless we use reliable means for LAA treatment. The risk of stroke after a maze management.

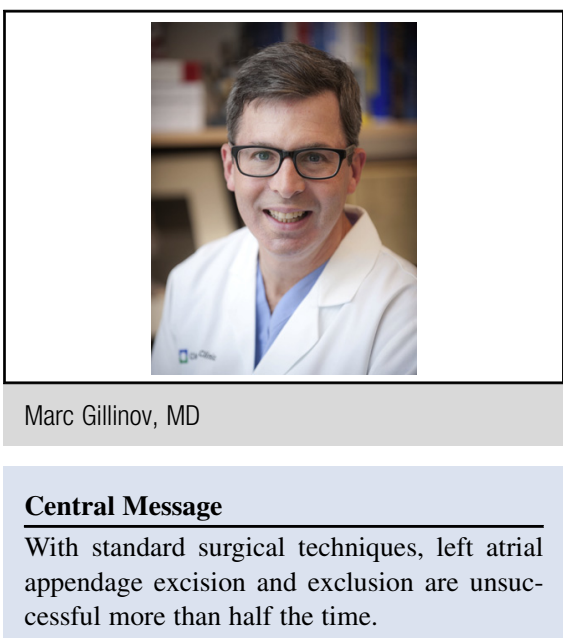

See Article page 1075.

procedure is very low, but we do not know how much of this reduced risk is attributable to the ablation and how much to LAA management. ${ }^{2}$ Whatever the relative contributions of the 2 procedures (ablation and LAA management) to stroke reduction, our surgical goal is to achieve success with both components of the operation.

\section{WHAT IS THE ROLE OF DEVICE-BASED LAA MANAGEMENT?}

Recognizing the limitations of traditional surgical management of the LAA, surgeons and industry have expressed interest in the development of device-based LAA management. The goals of these efforts include complete and permanent LAA exclusion with no risk of bleeding. Essentially, devices seek to address the shortcomings identified by Lee and colleagues. ${ }^{1}$ Early feasibility studies suggest that device-based surgical LAA management achieves success in more than $95 \%$ of cases. ${ }^{3}$ Modification of such devices for minimally invasive or thoracoscopic application may provide surgeons with an additional option for LAA

\section{HOW SHOULD SURGEONS MANAGE THE LAA TODAY?}

In the setting of surgical ablation for atrial fibrillation, whether as a stand-alone or concomitant procedure, LAA management should be considered an integral element of the operation. ${ }^{4}$ Device-based management provides the greatest likelihood of success. Transesophageal echocardiography is essential, regardless of the technique chosen. Lee and colleagues ${ }^{1}$ have demonstrated that we have 
been fooling ourselves with LAA management. On the basis of these revealing results, we should subscribe to one of the mantras of the British rock band The Who: We "Won't Get Fooled Again."

\section{References}

1. Lee RL, Vassallo P, Kruse J, Malaisrie SC, Rigolin V, Andrei AC, et al. A randomized, prospective pilot comparison of three atrial appendage elimination tech- niques: internal ligation, stapled excision, and surgical excision. J Thorac Cardiovasc Surg. 2016;152:1075-80.

2. Lee RL, Jivan A, Kruse J, McGee EC Jr, Malaisrie SC, Bernstein R, et al. Late neurologic events after surgery for atrial fibrillation: rare but relevant. Ann Thorac Surg. 2013;95:126-31; discussion 131-2.

3. Ailawadi G, Gerdisch MW, Harvey RL, Hooker RL, Damiano RJ Jr, Salamon T, et al. Exclusion of the left atrial appendage with a novel device: early results of a multicenter trial. J Thorac Cardiovasc Surg. 2011;142:1002-9. 1009.e1.

4. Cox JL. Mechanical closure of the left atrial appendage: is it time to be more aggressive? J Thorac Cardiovasc Surg. 2013;146:1018-27. 